Kansas State University Libraries

New Prairie Press

\title{
LINEAR-PLATEAU REGRESSION ANALYSIS AND ITS APPLICATION TO SELENITE ADSORPTION RATE
}

\author{
Bahman Shafii \\ Kevin C. Harper \\ Steven L. McGeehan
}

Follow this and additional works at: https://newprairiepress.org/agstatconference

Part of the Agriculture Commons, and the Applied Statistics Commons

\section{(c) (1) $\Theta$}

This work is licensed under a Creative Commons Attribution-Noncommercial-No Derivative Works 4.0 License.

\section{Recommended Citation}

Shafii, Bahman; Harper, Kevin C.; and McGeehan, Steven L. (1990). "LINEAR-PLATEAU REGRESSION ANALYSIS AND ITS APPLICATION TO SELENITE ADSORPTION RATE," Conference on Applied Statistics in Agriculture. https://doi.org/10.4148/2475-7772.1437

This is brought to you for free and open access by the Conferences at New Prairie Press. It has been accepted for inclusion in Conference on Applied Statistics in Agriculture by an authorized administrator of New Prairie Press. For more information, please contact cads@k-state.edu. 


\section{LINEAR-PLATEAU REGRESSION ANALYSIS AND ITS APPLICATION TO} SELENITE ADSORPTION RATE

Bahman Shafii, Statistical Programs, College of Agriculture Kevin C. Harper, Computer Services, and

steven I. MCGeehan, Division of Soil Sciences, College of Agriculture

University of Idaho

Moscow, ID 83843

\section{ABSTRACT}

Simple computational methods are presented which facilitate fitting regression models to response data exhibiting a plateau effect. The iterative statistical program (called PLATFOR) is written in FORTRAN (a SAS version is also available), and produces all relevant regression statistics, plots, and information on goodness of fit. The presented procedures are empirically valuable, since inear-plateau models have many useful applications in agriculture, especially in soil fertility and soil chemistry experiments. The technique was employed in an experiment designed to determine the effect of soil volcanic ash content on selenite adsorption. Ion chromatographic methods were used to investigate selenite adsorption in three acidic North Idaho surface soils of varying ash content. Equilibration periods of 0.5 to 12.0 hours were evaluated and the time required to reach maximum adsorption was determined using the PLATFOR program. It was concluded that both the rate and magnitude of selenite adsorption were influenced by soil volcanic ash content.

Reywords: Iinear-plateau models, regression analysis, selenite adsorption.

\section{INTRODUCTION}

In certain situations in agricultural research, especially those of soil fertility and soil chemistry, the response function exhibits a plateau effect. In such situations, it is often appropriate to approximate the underlying function with two intersecting linear lines (Figure 1) accounting for the sloping as well as the plateau segments of the response. Here, the emphasis is to approximate the real regression function, $E[Y(x)]$, which is certainly nonlinear (and asymptotic), with a sequence of low order polynomials or segmented models. Statistical estimation of the optimal plateau, the point at which increases in the input under investigation (e.g. fertilizer) would have no significant effect on the magnitude of the response (e.g. yield), may also be desirable and empirically useful. 
Linear-plateau regression analysis and its use in evaluating response to fertilizer nutrients was first introduced by Anderson and Nelson (1975). Agricultural researchers have since employed the techniques in describing other soil/crop situations (e.g. Mascagni and Cox, 1985; Potter et al., 1985; Mahler and MCDole, 1987; Singh, 1989). Procedures for fitting segmented curves and estimation of join points were introduced by Hudson (1966). However, computational methods outlining the iterative fitting program along with the associated statistics and the corresponding graphics have not been readily available. The main objective of this paper is to present simple computational techniques which facilitate fitting regression products to response data exhibiting a plateau effect. Empirical applications are demonstrated with reference to the selenite adsorption rate studies.

\section{Importance of Selenite Adsorption studies}

The role of selenium (Se) as an essential trace element in human and animal nutrition as well as its toxic effects at slightly higher concentrations has been well established (Adriano, 1986). Selenium is present in detectable but highly variable amounts in soils. High soil selenium levels can lead to toxic responses including "alkali disease" and "blind staggers" (Adriano, 1986). Selenium leaching from agricultural soils has caused a high incidence of deformity and mortality of waterfowl in the San Joaquin Valley of California (Deverel and Millard, 1986). On the other hand, low soil selenium levels can lead to nutritional disorders such as "white muscle disease" (Adriano, 1986).

The chemical form of selenium determines its transport and bioavailability in soils. Inorganic se occurs as metal selenides, elemental $\mathrm{Se}$, selenite $\left(\mathrm{SeO}_{3}{ }^{2-}\right)$, or as selenate $\left(\mathrm{SeO}_{4}{ }^{2-}\right)$. Selenate and selenite are the predominant forms in well aerated soils (Neal et al., 1987). Selenate is weakly adsorbed by soils while selenite forms a strong adsorption complex (Ahlrichs and Hossner, 1987; Neal et aI., 1987). Hence, the solubility of $\mathrm{Se}$ in soils depends on the predominant ionic form of $\mathrm{Se}$ and the interaction of the ionic species with adsorbing surfaces.

The rate of selenite adsorption decreases with equilibration time, often reaching a plateau. Equilibration periods for published selenite adsorption experiments are highly variable and range from 1 to $72 \mathrm{~h}$ (Rajan, 1979; Davis and Leckie, 1980; Singh et al., 1981). Researchers have relied on a visual (qualitative) estimation of adsorption data to identify the plateau. Hence, statistical comparison of adsorption rate and maxima is important for evaluating soil selenite behavior. 


\section{METHODS}

The iterative statistical program (PLATFOR) for performing the required regression analysis is written in Microsoft FORTRAN (version 3.0), and corresponding graphics are accomplished using Turbo PASCAL (version 5.0). Program codes are compiled into two exec files, one batch file, and five graphics drivers. The program requires minimal computer resources and runs easily on any IBM-PC (or compatible) machine. Copies of the program are available, upon request, from the senior author.

The first fitted equations considered by the program are of the form:

$$
Y=\beta_{0}+\beta_{1}[\min (X, A)]
$$

where $\beta_{0}$ is the intercept, and $\beta_{1}$ is the slope of the linear Iine up to the point $X=A$. The value of $A$ is selected by first setting $\bar{A}=\max (X), i . e .$, the largest observed value of $X$. Successive iterations will set $A$ equal to successively smaller and smaller observed values of $X$. At each iteration, the least square estimates of (1) along with the residual sum of squares, and the coefficient of determination $\left(R^{2}\right)$ are calculated. The plateau model corresponding to the smallest residual mean square is then selected, and the "optimal plateau" is indicated.

A second equation,

$$
Y=\beta_{0}+\beta_{1}[\min (X, A)]+\beta_{2}[\max (X, A)-A]
$$

is also fitted to enable testing for the existence of significant slope $\left(\beta_{2}\right)$ beyond the point $\mathrm{X}=\mathrm{A}$ (Potter et al., 1985). At this point the program provides all relevant regression statistics, including parameter estimates, standard error of estimates, $t$ and corresponding $p$ values (probability of obtaining a larger value of $|t|$ under the hypothesis $\mathrm{H}_{\mathrm{o}}$ : parameter $=0$ ).

Graphics options include scatter plot, scatter plot with the fitted plateau regression line, and scatter plot with plateau and joined lines. These plots along with other statistics provided by the program are extremely useful in evaluating the goodness of fit as well as appropriateness of assuming a linear-plateau model to approximate a specified response data.

A SAS implementation of the PLATFOR program may alternatively be considered for the analysis. SAs codes required to perform the statistical computations and graphics are outlined in Table 1. This program was written using SAS (Statistical Analysis System) Version 5.18, and procedures MATRIX (SAS Statistics), and GPlot (SAS Graphics). The program can be converted to IML codes via the MATIMI Procedure. 


\section{APPIICATION}

In inear plateau regression analysis was employed in an experiment designed to evaluate selenite adsorption in three north Idaho soils of varying volcanic ash content. Samples of the surface mineral horizon of each soil were air-dried and ground to pass a $2 \mathrm{~mm}$ sieve. Sodium fluoride $\mathrm{pH}$ and oxalate-extractable $\mathrm{Al}$ and $\mathrm{Fe}$ values were used as indicators of volcanic ash content (Table 2). The Huckleberry silt loam, which exhibited the highest sodium fluoride $\mathrm{pH}$ and highest extractable aluminum and iron values, was assumed to have the highest volcanic ash content. Rates of selenite adsorption were determined using soil suspensions (1:25 w/v) containing $2.0 \mathrm{mg} / \mathrm{L}$ selenite. Equilibration times ranged from 0.5 to 12 hr with three replications. Soluble selenite was determined using a Dionex $4000 i$ Ion Chromatograph with Dionex AS4a separator column and $1.5 \mathrm{mM} \mathrm{Na} \mathrm{CO}_{3}+1.0 \mathrm{mM} \mathrm{NaHCO}$ eluent. Adsorption data were analyzed using the PLATFOR program.

Scatter plots along with the fitted plateau regression Iine and the corresponding prediction equation for each specified soil are given in Figure $2(a, b$, and $c)$. It is evident that the linear-plateau model has provided a good fit for the adsorption data in all cases. All regression coefficients were statistically significant $(P<0.01)$, and the tests for the $\beta_{2}$ parameter (Eqn. 2) indicated the lack of significant slope beyond the point of optimal plateau in each case.

Maximum adsorption was obtained in 4,6 , and 8 hr in the Huckleberry, Helmer, and Santa soils, respectively (Figure 2). Hence, the time required to reach the adsorption plateau decreased as the soil volcanic ash content increased. Furthermore, the greatest selenite adsorption occurred in the Huckleberry soil, which exhibited the greatest volcanic ash content (Figure 2). Thus, the results indicate that both the rate and magnitude of selenite adsorption depended on the soil volcanic ash content. 
IV. CONCLUSION

The PLATFOR program offers a simple computational technique which facilitates fitting regression models to empirical data exhibiting a plateau effect. The program is easy to run and provides relevant regression statistics and plots that can be useful in evaluating the suitability of linear-plateau models in approximating a specific response function. Further extensions of the program (multi-input situations, confidence intervals for the optimal plateau, comparison of plateau regression lines, other splining techniques) are being considered, and the authors intend to include the findings in future work.

\section{ACRNOWLEDGEMENTS}

Idaho Agricultural Experiment Station manuscript number 9001. The authors wish to thank Dr. Denny V. Naylor for his assistance in the selenite adsorption studies, and an anonymous referee for comments and suggestions made on a previous draft of this paper. 


\section{REFERENCES}

Adriano, D.C. 1986. Trace Elements in the Terrestrial Environment. Springer-Verlag, New York.

Ahlrichs, J.S., and L.R. Hossner. 1987. Selenate and selenite mobility in overburden by saturated flow. J. Environ. Qual. 16:95-98.

Anderson, R.I., and I.A. Nelson. 1975. A family of models involving intersecting straight lines and concomitant experimental designs useful in evaluating response to fertilizer nutrients. Biometrics 31:303-318.

Davis, J.A., and J.O. Leckie. 1980. Surface ionization and complexation at the oxide/water interface. 3. Adsorption of anions. J. Colloid Interface Sci. $74: 32-43$.

Deverel, S.J., and S.P Millard. 1986. Distribution and mobility of selenium and other trace elements in shallow ground water of the western San Joaquin Valley, California. U.S. Geological Survey, Open-File Report 86-538.

Hudson, D. J. 1966. Fitting segmented curves whose joined points have to be estimated. JASA 64:10961129.

Mahler, R.L., and R.E. MCDole. 1987. Effect of soil pH on crop yield in northern Idaho. Agron. $J$. $79: 751-755$.

Mascagni, H.J. Jr., and F.R. Cox. 1985. Effective rates of fertilization for correcting manganese deficiency in soybeans. Agron. J. 77:373-375.

Neal, R.H., G. Sposito, K.M. Holtzclaw, and S.J. Traina. 1987. Selenite adsorption on alluvial soils: I. Soil composition and $\mathrm{pH}$ effects. Soil Sci. Soc. Am. J. 51:1161-1165.

Potter, D.A., B.L. Bridges, and F.C. Gordon. 1985. Effect of $N$ fertilization on earthworm and microarthropod population in kentucky bluegrass turf. Agron. J. 77:367-372.

Rajan, S.S.S. 1979. Adsorption of selenite, phosphate and sulphate on hydrous alumina. J. Soil Sci. $30: 709-718$. 
Singh, K.P. 1989. Statistical models for the analysis of dose-response data. Proc. Conference on Applied statistics in Agriculture, April 30-May 2. G. A. Milliken and J.R. Schwenke (EdS.). Kansas State University, Manhattan, Kansas.

Singh, M., N. Singh, and P.S. Relan. 1981. Adsorption and desorption of selenate and selenite on different soils. Soil Sci. 132:134-141. 
Figure 1. Linear Plateau Response.

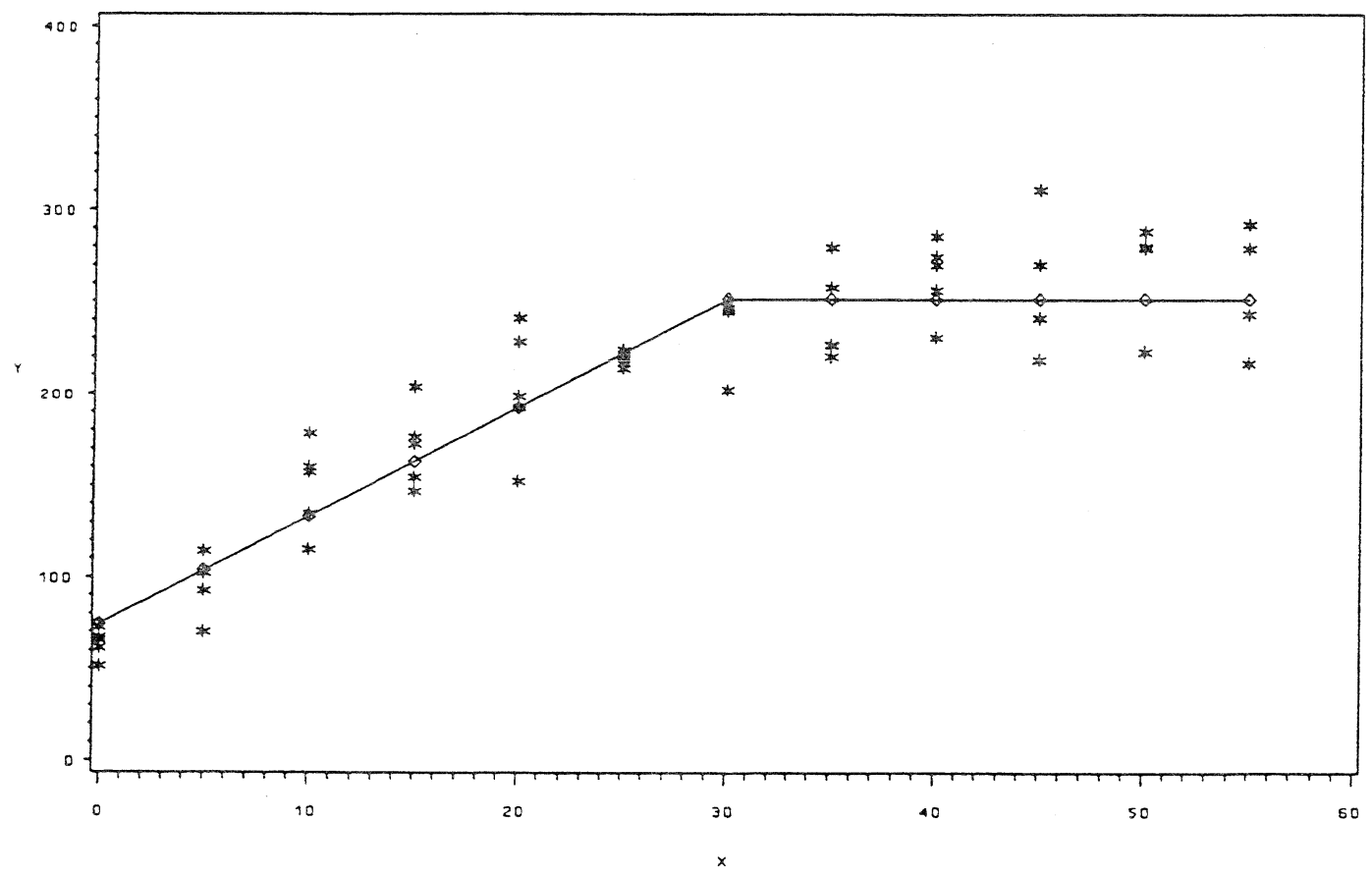


Table 1. SAS Implementation of the PLATFOR Program.

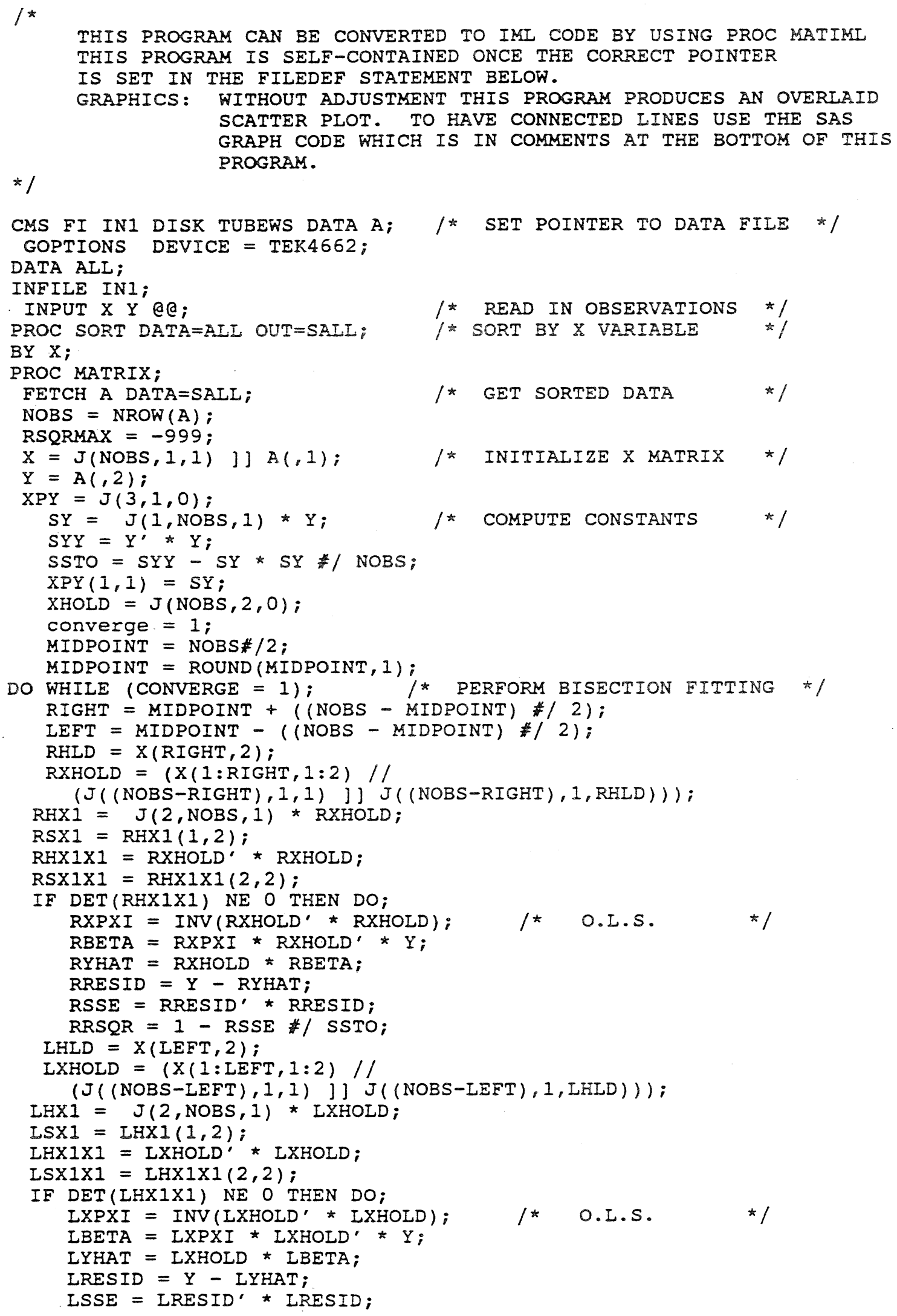




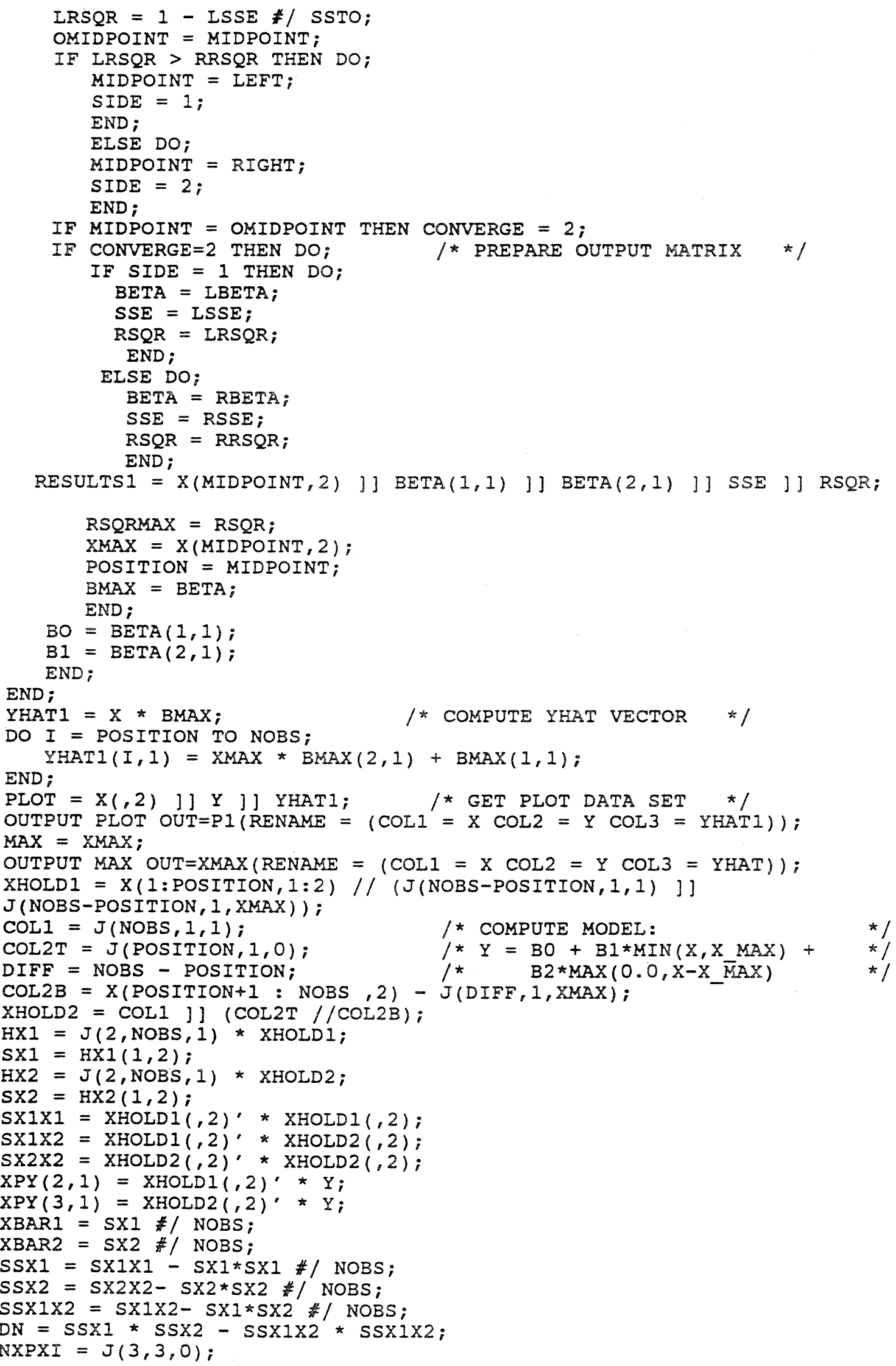




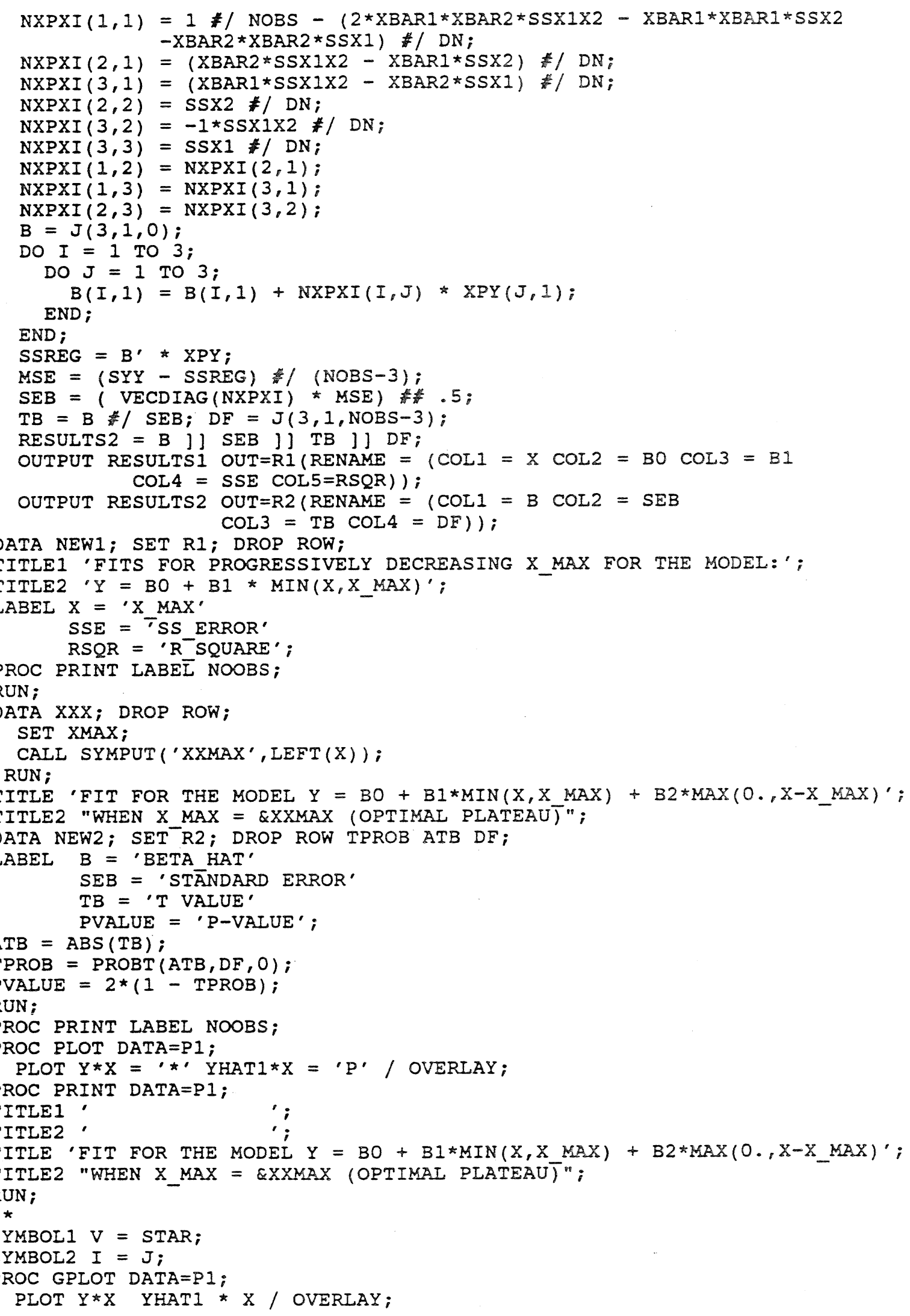


Table 2. Selected properties of the Huckleberry, Helmer, and Santa silt loam soils.

\begin{tabular}{||l|l|l|r|r|r||}
\hline Soil & $\begin{array}{c}\text { Taxonomic } \\
\text { Classification }\end{array}$ & $\mathrm{pH} *$ & \multicolumn{2}{|c|}{$\begin{array}{c}\text { NaF } \\
\mathrm{pH}\end{array}$} & $\begin{array}{c}\text { oxalate-extractable } \\
\text { Al }\end{array}$ \\
\hline Huckleberry & Typic vitrandept & 6.6 & 9.9 & 19.5 & 7.6 \\
Helmer & Andepic Paleboralf & 6.5 & 9.3 & 10.2 & 5.9 \\
Santa & Ochreptic Fragixeralf & 6.0 & 7.8 & 1.7 & 4.8 \\
\hline
\end{tabular}

* saturated water-paste 
Figure 2. Adsorption Response for (a) Huckleberry

(b) Helmer (c) Santa Soils and (d) Overlay of Mean Responses.

a.

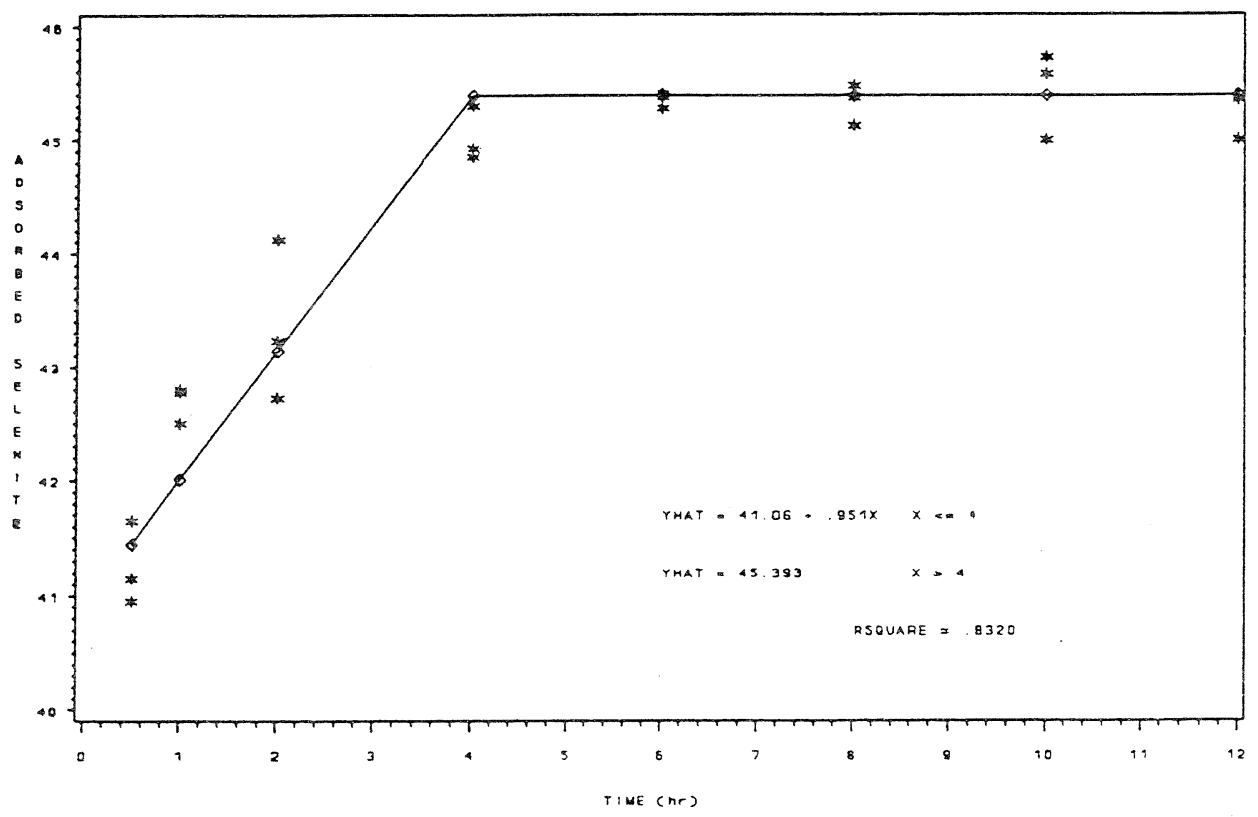

b.

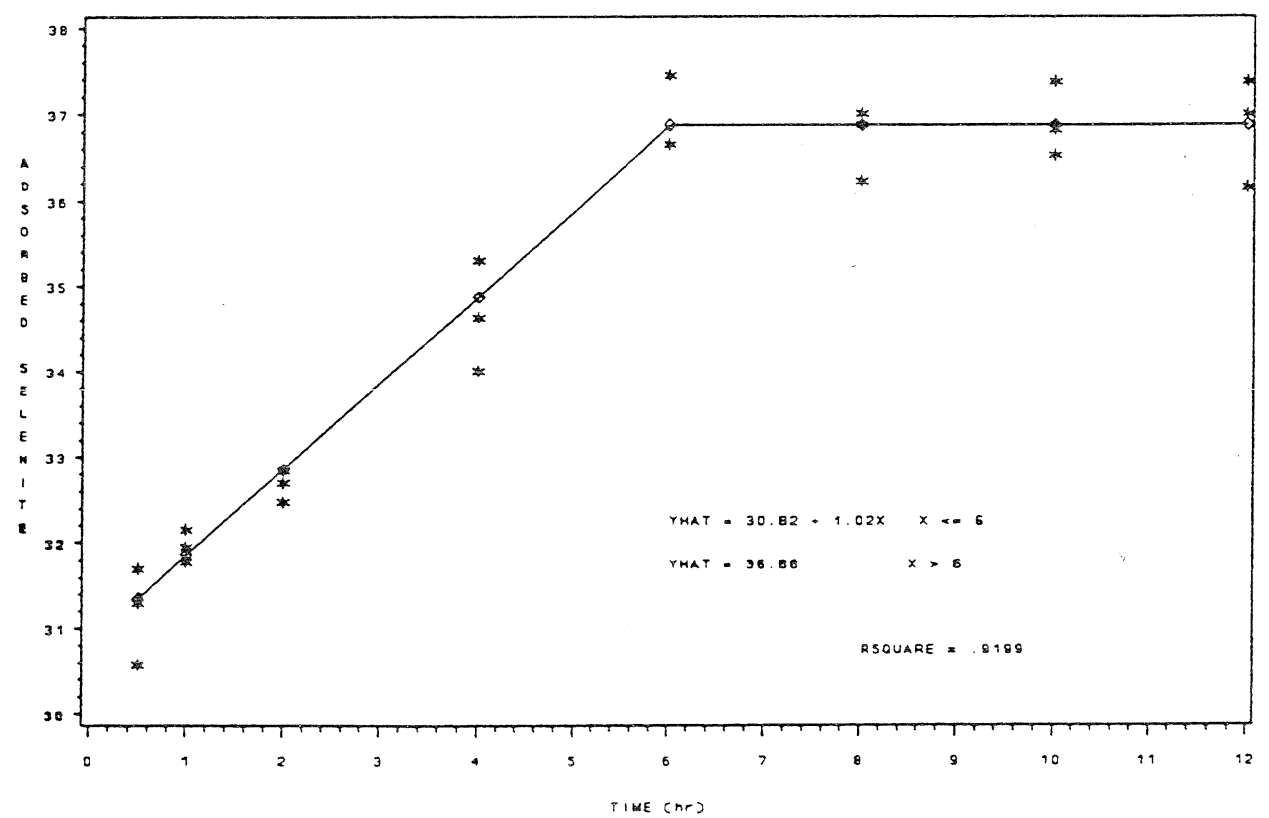


C.

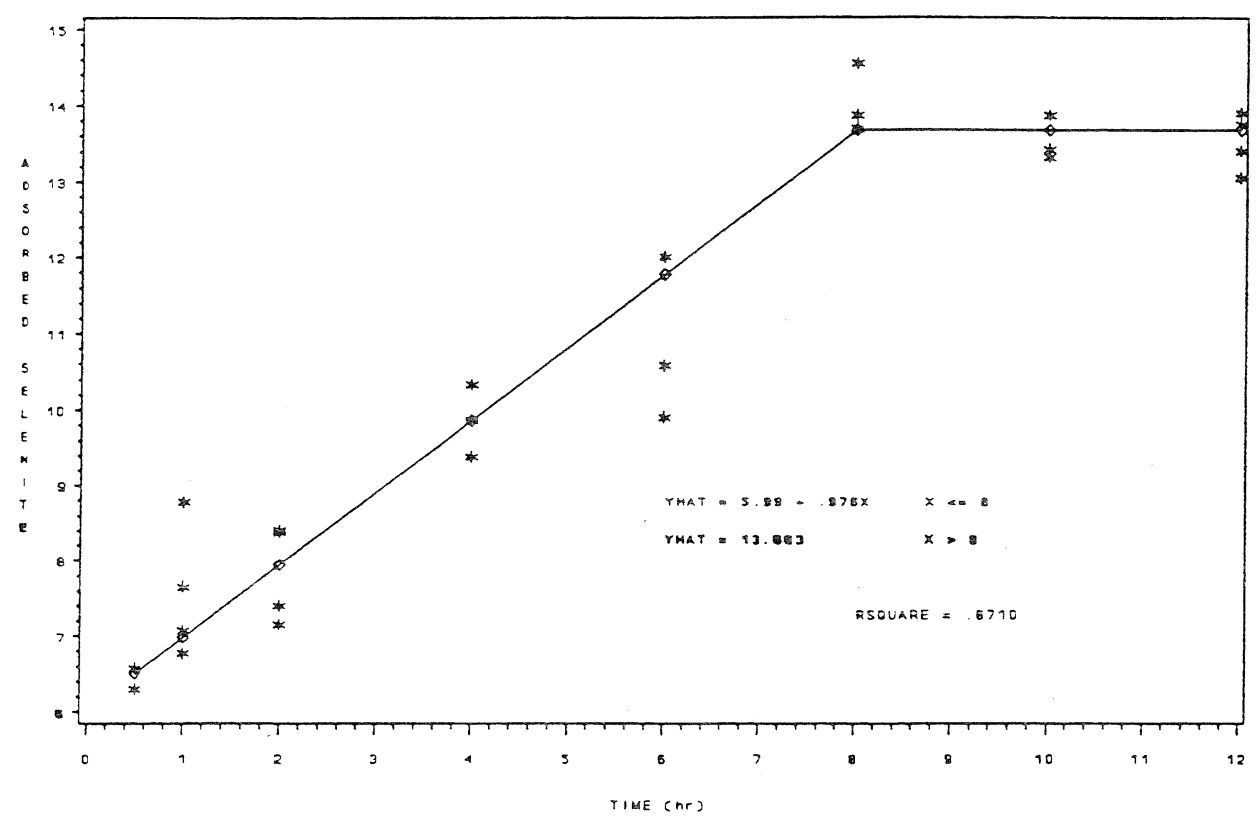

d.

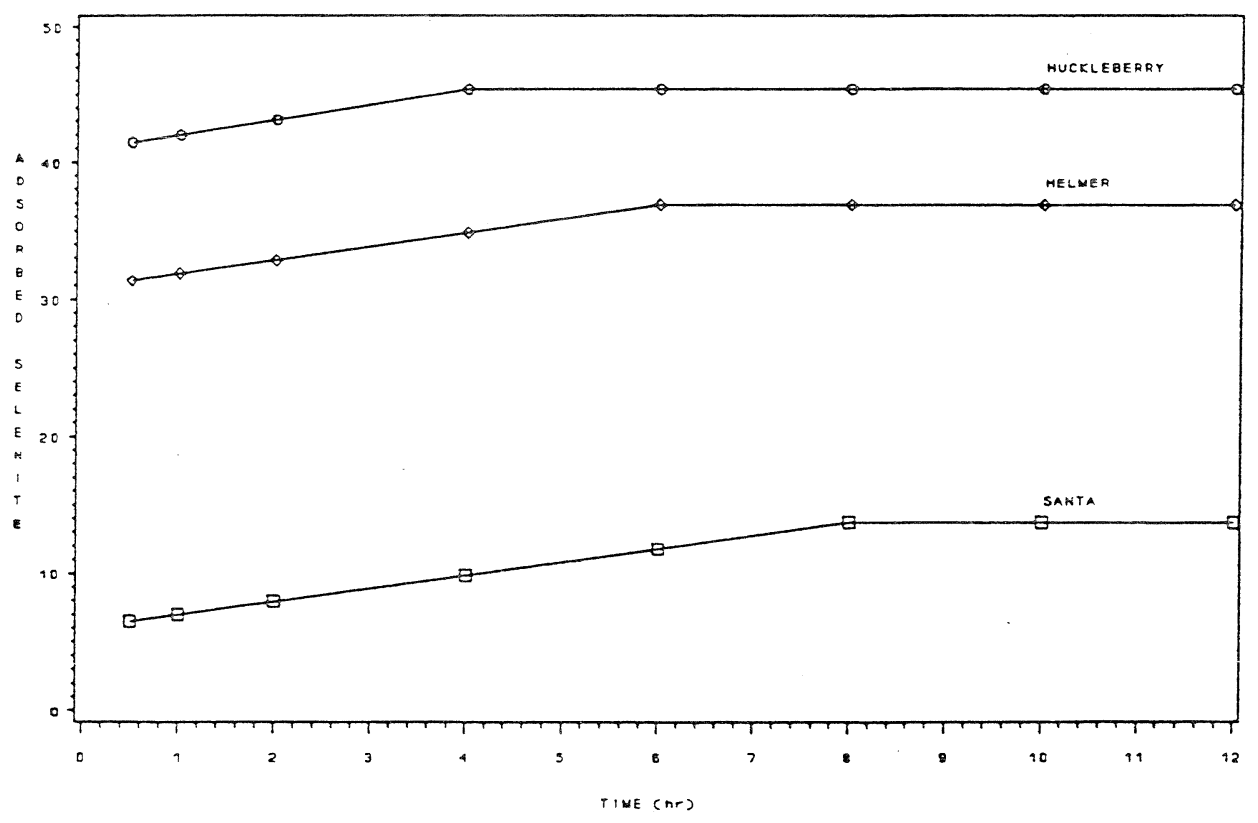

